\title{
Blended Learning em um Curso de Desenho de Moda: combinação de metodologias facilitadoras no processo de ensino-aprendizagem
}

\author{
Jucélia Tramontin Dalpias, \\ Rafaela Bett Soratto, \\ Lilian Venâncio Nolla da Silva, \\ Grasiela Ghisleri, \\ Luziana Quadros da Rosa
}

\section{INTRODUÇÃO}

O artigo aborda a metodologia de cursos mistos em um Curso de Desenho de Moda - desenvolvido na plataforma MOODLE, com estudantes egressos do Instituto Federal de Santa Catarina (IFSC), campus Araranguá. Os alunos egressos possuem conhecimento no assunto, pois estudaram o Desenho de Moda na modalidade presencial. O objetivo geral do artigo pretende avaliar o curso misto, na adequação das modalidades de ensino a distância e presencial, verificando os impactos da utilização dessa metodologia que é denominada de blended learning.

Segundo Chaves Filho (2006), curso misto é um termo utilizado que apresenta características diferenciadas, com variedade e combinação de métodos de aprendizagem, gerando interação e conhecimento. Ele se distingue, pois integra vários métodos como áudio, TV interativa, multimídia, internet, web etc. Como supracitado, essa modalidade de cursos mistos é chamada de blended learning; para Valente (2014), o blended learning combina atividades presenciais e atividades educacionais a distância, que são realizadas por meio das Tecnologias Digitais de Informação e Comunicação (TDIC).

Dessa forma, a pesquisa se inicia com uma breve contextualização sobre os cursos mistos e seu respectivo funcionamento. Na metodologia, apresentam-se as etapas da investigação-ação. A seguir, os resultados apresentados demonstram a avaliação do Curso Misto de Desenho de Moda na perceção dos estudantes. Por fim, são apresentadas as considerações finais da pesquisa. 


\section{CONTEXTO DOS CURSOS MISTOS}

A Educação a Distância (EaD), de acordo com o Censo 2010 (INEP, 2011), é a modalidade que mais vem crescendo no Brasil. Ao longo dos anos, essa modalidade de ensino vem sofrendo transformações:

[...] $1^{a}$ geração: ensino por correspondência; $2^{a}$ geração: tele-educação através da rádio, televisão e cassetes de áudio e vídeo; $3^{a}$ geração: serviços temáticos baseados em comunicações assíncronas, tais como e-mail e fóruns de discussão, para completar páginas Web, CD-ROM e outros suportes digitais (LIMA; CAPITÃO, 2003; CARVALHO; CARDOSO, 2004 apud GONÇALVES, 2007, p. 2-3).

Observando-se a evolução da EaD no Brasil, Suhr e Ribeiro (2010, p. 26) afirmam que "pode ser uma valiosa ferramenta em prol da democratização de ensino no Brasil”, pois oferece ensino de qualidade, respeitando as especificidades de cada discente, gerando possibilidades e condições de acesso a todos que não dispõem de tempo para cursarem o ensino presencial. Dessa forma, o sistema misto de ensino, que compreende os cursos mistos, Blended Learning, não é um tema recente no Brasil, pois já vem sendo discutido há vários anos. Segundo Castro (2007), o mesmo estava presente desde a década de 1970, nos projetos de educação a distância por radiodifusão. Então, blended learning é um conceito de educação caracterizado pelo uso de soluções mistas.

O mesmo utiliza uma diversidade de métodos de aprendizagem, que ajudam acelerar o aprendizado e garantem a colaboração entre os participantes, permitindo e gerando a troca de conhecimento. O conceito faz uso de integração de diversos métodos institucionais (estudos de caso, demonstração, jogos, trabalhos de grupo), métodos de apresentação (áudio, groupware, TV interativa, teleconferência, sistemas de apoio à performance, multimídia) com métodos de distribuição (TV a cabo, CD-ROM, e-mail, internet, intranet, telefone voicemail, web), em resposta ao planejamento institucional previamente estabelecido (CHAVES FILHO et al., 2006, p. 84).

O blended learning também é caracterizado como ensino híbrido, ou seja, é uma metodologia de aprendizado on-line e off-line, que proporciona ao estudante participar de um curso misto, em uma modalidade de b-learning "quando parte das atividades são realizadas totalmente a distância e parte é realizada em sala de aula, caracterizando o que tem sido denominado de ensino híbrido, misturado ou blended learning" (VALENTE, 2014, p. 84). Esse tipo de curso integra as plataformas de ensino, baseadas nas TDIC, contribuindo em todo o pro- 
cesso de forma significativa, adaptando os momentos de ensino a distância e presencial.

Para Machado et al. (2014), essa é uma realidade que vem sendo potencializada pela EaD com o objetivo de contribuir para os processos de formação do indivíduo, sem substituir modelos de ensinar e aprender. Esse contexto inovador de ensino dar-se-á devido a inserção das TDIC. Nesse sentido, a modalidade de ensino de cursos mistos, conforme Rabello e Haguenauer (2011), apontam para o aprendizado eletrônico, e-learning, e a aprendizagem móvel, m-learning, que estão mudando radicalmente os ambientes e contextos de aprendizagem para o ensino do Brasil. Assim, essa modalidade oportuniza ocasiões presenciais e períodos em que o aluno estuda sozinho, com autonomia, em um ambiente virtual. No entanto:

[...] o termo ainda está sujeito ao perigo de ser confundido com um método em que apenas se misturam as duas modalidades de ensino/aprendizagem: face a face e online, multiplicando apenas os canais de acesso ao conhecimento por parte do aluno. A estratégia b-learning é muito mais do que uma multiplicação de canais, é uma combinação de métodos de ensino/aprendizagem. (MATEUS FELIPE; ORVALHO, 2004, p. 217).

Para Giglio e Souza (2013), o desenvolvimento das tecnologias digitais tornou-se cada vez mais presente, possibilitando ao indivíduo uma maior interatividade com o fluxo de informações. A comunicação virtual rápida, dinâmica e flexível são fatores favoráveis para o avanço da humanidade, bem como as potencialidades do ambiente cibernético, que favorecem o desenvolvimento da criatividade humana, segundo o autor. Entretanto, esses fatores são diferenciais e fundamentais na forma de aprendizagem mista, pois, como visto, essa modalidade está intrinsecamente englobada em dois momentos: presenciais e a distância, e a sua eficácia está na convergência dessa troca, que depende da metodologia aplicada, da qualidade do ensino e, consequentemente, da efetivação da aprendizagem.

\subsection{FUNCIONAMENTO DOS CURSOS MISTOS}

Para que ocorra essa convergência da modalidade de cursos mistos, articulam-se mudanças também nos papéis de docentes e discentes. O blended learning proporciona maior interação entre pares e oportuniza momentos e espaços adequados para que a aprendizagem aconteça.

Os discentes, apesar da autonomia, não se encontram totalmente a distância e isolados no processo de aprendizagem, ou até mesmo, em sala de aula em 
um determinado momento presencial, sem opção de organizar seu próprio tempo de estudo. Existe uma junção das instâncias presencial e on-line, na qual os estudantes conseguem ter o contato com o professor, que agora passa a ser o mediador do conhecimento, sanando dúvidas e oportunizando momento de estudos aos discentes.

Baseado nesse contexto, busca-se superar as dificuldades encontradas na adequação do funcionamento dos cursos mistos, considerando a mescla de diferentes métodos e abordagens pedagógicas, que podem ocorrer de forma assíncrona ou síncrona, conforme o Quadro 1.

\begin{tabular}{|l|l|}
\hline \multicolumn{1}{|c|}{ Formato } & \multicolumn{1}{c|}{ Atividades } \\
\hline Síncrono físico & $\begin{array}{l}\text { Aulas face a face; conferência em grande grupo; } \\
\text { resolução de problemas em pequenos grupos; percursos } \\
\text { no terreno (visitas e trabalhos exteriores); seminários e } \\
\text { workshops com peritos convidados. }\end{array}$ \\
\hline Síncrono on-line & $\begin{array}{l}\text { Encontros virtuais: chat, videoconferência e acessos } \\
\text { remotos; seminários na Web com peritos convidados; } \\
\text { mensagens instantâneas (tipo MSN, ICQ, SMS e MMS). }\end{array}$ \\
\hline Assíncrono & $\begin{array}{l}\text { Documentos impressos (guiões e textos de apoio); } \\
\text { documentos em formato digital (CD-Rom e DVD); páginas } \\
\text { na Web (pesquisa dirigida e livre); Management Learning } \\
\text { System (LMS): conteúdos, questionários, inquéritos, } \\
\text { simulações, webseminars, avaliação e ferramentas de } \\
\text { comunicação (e-mail interno e listas de conversação); } \\
\text { e-mail externo (ESECWeb). }\end{array}$ \\
\hline
\end{tabular}

Quadro 1: Métodos e abordagens pedagógicas para o Ensino a Distância.

Fonte: Adaptado de Mateus Filipe e Orvalho (2004).

Por fim, nota-se no Quadro 1 que com essa abordagem pedagógica, proposta por Mateus Filipe e Orvalho (2004), o discente possui autonomia, atuando em um mesmo curso em três momentos mistos: o síncrono físico, o síncrono on-line e o assíncrono, em que para o melhor aproveitamento e desenvolvimento do estudo proposto utilizam-se recursos digitais, possibilitando a interação com colegas e professores para a disseminação do conhecimento.

\section{METODOLOGIA}

Quanto à abordagem metodológica, foi realizada uma investigação-ação, em que se avalia um curso misto, por meio das percepções de 11 estudantes que 
cursaram na Plataforma MOODLE, pelo método blended learning, o aperfeiçoamento em Desenho de Moda, nos cursos Ensino Técnico em Produção de Moda e Curso Superior de Tecnologia em Design de Moda, do Instituto Federal de Santa Catarina (IFSC), campus Araranguá.

Para Tripp (2005), uma investigação-ação representa a tentativa continuada, de modo sistêmico e empírico, de aprimorar uma prática. Diante dessa proposta, realizou-se uma aplicação de conteúdos que foram ministrados na disciplina de Educação a Distância, do Programa de Pós Graduação em Tecnologias da Informação e Comunicação da Universidade Federal de Santa Catarina (PPGTIC/UFSC), campus Araranguá. O desafio proposto pelos professores que conduziram a disciplina foi que cada grupo de discentes, mestrandos do programa, estruturassem um tipo de curso para posteriormente apresentar o resultado do seu estudo.

Às autoras deste trabalho coube, então, o planejamento de um curso na modalidade mista. A ideia inicial foi elaborar o curso de atualização de Desenho de Moda, baseado na metodologia blended learning. Para tanto, foi proposto um planejamento do curso, que considerou vinte encontros, nos quais definiram-se aspectos que consideravam desde a sua estrutura, o local presencial e a plataforma tecnológica para a sua aplicação, incluindo os aspectos administrativos de formas de ingresso, oferta, carga horária, número de vagas, turno, bem como os aspectos pedagógicos que contemplavam a construção da ementa, objetivos, metodologia do curso, entre outros.

Após a elaboração e aplicação do curso, os dados da pesquisa foram coletados através de um questionário, contemplando nove questões estruturadas, com a finalidade de verificar a percepção dos 11 estudantes, por meio da abordagem qualitativa, quanto à avaliação e participação na oferta de um curso misto.

\section{PROPOSTA DO CURSO MISTO}

Nessa seção, mostram-se as etapas de construção do curso de atualização em Desenho de Moda. O curso tem por finalidade propor conhecimento sobre a temática de desenho de moda, e o estudante, além de assistir aos vídeos do curso, tem a oportunidade de seguir e realizar as atividades através do acompanhamento de conteúdos didáticos e de interagir com colegas e professores para resolução de dúvidas e atividades práticas.

As aulas presenciais foram planejadas para acontecer em 20 encontros, de acordo com a atividade proposta, conforme o cronograma desenvolvido. Desse modo, a primeira etapa de elaboração, refere-se ao planejamento da estrutura do curso. Nessa etapa, definiu-se o local das aulas presenciais, o período de oferta, 
o tipo de modalidade, a carga horário e o turno.

A segunda etapa, culminou com a elaboração do Plano de Ensino e construção de um cronograma, considerando aspectos da metodologia blended learning, que foi estruturado a fim de esclarecer as competências e habilidades desejadas para os cursistas. Além disso, também foram definidas as bases tecnológicas e a escolha da plataforma MOODLE para aplicação virtual do curso, bem como houve a seleção das bibliografias correspondentes para fundamentação teórica.

O objetivo geral do curso misto criado visa "possibilitar o aprendizado no Desenho de Moda, contribuindo para a qualificação na criação de produtos de moda e nos serviços prestados para as indústrias de confecção”. A ementa do curso misto prevê que o curso de qualificação profissional em Desenho de Moda funcione através de atividades realizadas individualmente e em colaboração, na sala de aula online e presencial, na qual o estudante aprende sobre croqui de moda e sobre as técnicas para o seu desenvolvimento dentro das proporções cânones da figura humana feminina, masculina e infantil, possibilitando a esse estudante conhecer e desenhar os diferentes tipos de vestimentas: saias, calças, mangas, decotes, golas, bolsas, sapatos e chapéus do vestuário feminino.

Durante o processo, o cursista desenvolve seu próprio estilo de desenho de moda, através de técnicas para a estilização dos desenhos. Ainda aprende como colorir os desenhos com os mais variados materiais de coloração existentes no mercado, como lápis de cor, giz, canetas especiais para pintura, carvão, grafite etc. Dessa forma, o aluno será capacitado para aprender sobre a importância do desenho de moda nas indústrias de confecção, ateliês de costura, comércio e como trabalhar de forma empreendedora terceirizando os serviços de desenho para o mercado da moda.

Para atingir o objetivo pretendido no curso, a mediação pedagógica será proposta por meio de materiais impressos e online, divididos em módulos, conforme as atividades sugeridas. $\mathrm{O}$ modo de participação dar-se-á por meio presencial e virtual. As aulas presenciais deverão funcionar para mostrar as técnicas mais complexas do desenho, atendimento individual, correção das atividades e a resolução de dúvidas de modo colaborativo. Já as aulas online são propostas por meio de conteúdos e vídeos digitais, com as técnicas a serem realizadas durante o período do curso, na plataforma virtual.

O Quadro 2 ilustra como o plano de ensino do curso misto foi estruturado, a fim de esclarecer as competências e habilidades esperadas dos cursistas, além de definir as bases tecnológicas e bibliografias a serem empregadas em atendimento à metodologia adotada. 


\section{Competências}

Compreender o desenho de moda na proporção cânone e suas diversas formas de estilização do corpo humano, roupas, acessórios e técnicas de coloração para a aplicação nos desenhos.

\section{Habilidades}

- Traçar as partes do corpo humano: mãos, pés, braços, pernas, rostos e cabelos; Representar a figura humana na adequada proporção cânone (masculino feminino e infantil);

- Identificar e construir os diferentes tipos de vestimentas na moda, demonstrando as ações das dobras do tecido, forma e volume, por meio dos princípios de luz e sombra;

- Identificar e desenvolver croqui de moda estilizado;

- Praticar as diferentes técnicas de pintura para o desenho de moda;

- Exercitar o traçado de diversos tipos de acessórios (sapatos, bolsas, bijuterias etc.);

Bases Tecnológicas

Desenho de moda, proporção, estilização do desenho de moda, técnicas de pintura e criatividade.

Bibliografia Básica

[1] ABLING, Bina. Desenho de moda. [Traduzido por Maria Izabel Branco Ribeiro]. São Paulo: Blucher, 2011. v. 1/ Bina Abling.

[2] MORRIS, Berthan. Fashion illustrator: manual do ilustrador de moda. São Paulo: Cosac Naify, 2007.

[3] VOSS, Denise. Desenho de moda e anatomia. Rio de Janeiro: Copyright, 2009. Bibliografia Complementar

[1] DRUDI, Elisabetta et al. Dibujos de figurines. Para el diseño de moda. Amsterdan: The Pepin Press, 2001.

[2] FEYERABEND, F. V. Figurines de moda. Barcelona: GG Moda, 2007.

Quadro 2: Plano de ensino do curso de Desenho de Moda Fonte: Autoras (2016).

Ainda nessa etapa, de modo a executar a proposta do curso misto, elaborou-se um cronograma onde todas as aulas foram definidas, estabelecendo-se a carga horária adequada, o modo pelo qual os conteúdos seriam ministrados, online e presencialmente, e o tipo de atividades que seriam desenvolvidas pelos 
cursistas de acordo com metodologia pedagógica estabelecida. O Quadro 3 ilustra esse cronograma.

\begin{tabular}{|l|l|l|l|}
\hline & CH & \multicolumn{1}{|c|}{ Conteúdo/Atividade } & Estratégia Didáticas \\
\hline 1 o & 4 & $\begin{array}{l}\text { Apresentação do curso e do plano de ensino. } \\
\text { Introdução do conteúdo/ Importância do } \\
\text { desenho de moda. }\end{array}$ & PRES/LAB/AED/APO \\
\hline $2^{\circ}$ & 4 & $\begin{array}{l}\text { Atividade de coordenação motora e desenho } \\
\text { de observação através de planejamento, luz e } \\
\text { sombra. }\end{array}$ & ON/APO/VDO/TI \\
\hline $3^{\circ}$ & 4 & $\begin{array}{l}\text { Representar a figura humana feminina na } \\
\text { adequada proporção (cânones), na forma } \\
\text { estática. }\end{array}$ & ON/APO/VDO/TI \\
\hline $4^{\circ}$ & 4 & $\begin{array}{l}\text { Representar a figura humana feminina na } \\
\text { adequada proporção (cânones), na forma } \\
\text { dinâmica. }\end{array}$ & ON/APO/VDO/TI \\
\hline $5^{\circ}$ & 4 & $\begin{array}{l}\text { Correção das atividades, resolução das dúvidas } \\
\text { e demonstração ao vivo da figura humana } \\
\text { feminina na adequada proporção (cânones), na } \\
\text { forma dinâmica com tônus muscular. }\end{array}$ & PRES/LAB/ATI/AED/ \\
APO/TI
\end{tabular}




\begin{tabular}{|l|l|l|l|}
\hline & $\mathrm{CH}$ & \multicolumn{1}{|c|}{ Conteúdo/Atividade } & Estratégia Didáticas \\
\hline $13^{\circ}$ & 4 & $\begin{array}{l}\text { Apresentação da Terminologia do Vestuário: } \\
\text { desenho de roupas e acessórios utilizando base } \\
\text { de croqui na construção do desenho. }\end{array}$ & ON/APO/VDO/TI \\
\hline $14^{\circ}$ & 4 & $\begin{array}{l}\text { Estilização do croqui de moda feminino: } \\
\text { proporção nove cabeças. }\end{array}$ & ON/APO/VDO/TI \\
\hline $15^{\circ}$ & 4 & $\begin{array}{l}\text { Aula presencial para correção das atividades e } \\
\text { resolução das dúvidas. Demonstração ao vivo } \\
\text { da técnica de coloração com lápis de cor. }\end{array}$ & $\begin{array}{l}\text { PRES/LAB/TI/AED/ } \\
\text { APO/ATI }\end{array}$ \\
\hline $16^{\circ}$ & 4 & $\begin{array}{l}\text { Técnica de coloração com lápis de cor e } \\
\text { aquarela. }\end{array}$ & ON/APO/VDO/TI \\
\hline $17^{\circ}$ & 4 & $\begin{array}{l}\text { Técnica de coloração com canetas especiais } \\
\text { para pintura (pantone). }\end{array}$ & ON/APO/VDO/TI \\
\hline $18^{\circ}$ & 4 & $\begin{array}{l}\text { Representar a figura infantil na adequada } \\
\text { proporção cânone de acordo com cada idade. }\end{array}$ & ON/APO/VDO/TI \\
\hline $19^{\circ}$ & 4 & $\begin{array}{l}\text { Recuperação dos conteúdos para os alunos } \\
\text { que não atingiram médias ou apresentaram } \\
\text { dificuldades no decorrer do curso: finalização } \\
\text { das atividades para avaliação. }\end{array}$ & PRES/LAB/APO/ATI \\
\hline $20^{\circ}$ & 4 & $\begin{array}{l}\text { Encerramento do semestre com feedback } \\
\text { das notas e avaliação do curso por parte dos } \\
\text { alunos. }\end{array}$ & PRES/ LAB / AED \\
\hline
\end{tabular}

Quadro 3: Cronograma dos 20 encontros, carga horária (CH), conteúdos/atividades e as estratégias didáticas do curso de desenho de moda.

Fonte: Autoras (2017).

Legenda das estratégias didáticas: Presencial (PRES); online (ON); Apostila(APO); Vídeo Explicativo (VDO); Aula Expositiva Dialogada (AED); Trabalho Individual (TI); Aula em Laboratório (LAB); Atendimento Individual (ATI).

A última etapa refere-se à avaliação do curso misto. Nessa etapa, com o intuito de demonstrar a avaliação da modalidade proposta, realizou-se a aplicação do questionário, que buscou identificar as percepções dos estudantes a respeito do curso. Os respondentes são egressos do curso presencial Técnico em Produção de Moda do IFSC, campus Araranguá, o que proporcionou uma melhor análise comparativa quanto à aplicação de curso na modalidade presencial e o curso elaborado pelas autoras, ofertado na modalidade híbrida. 


\subsection{RESULTADOS DA AVALIAÇÃO DO CURSO MISTO}

Nessa seção, os resultados demonstram as percepções dos estudantes quanto à avaliação do curso do misto, por meio de uma análise comparativa, em relação ao mesmo tipo de curso que foi oferecido (primeiramente) na modalidade presencial.

Os respondentes tiveram que apontar quais aspectos consideravam mais significativos, comparando os processos de experiências de ensino da modalidade presencial e posteriormente da aprendizagem mista. Apenas 9,1\% dos respondentes alegaram não haver diferença entre os processos de aprendizagem, em comparação aos outros $81,8 \%$, que confirmaram ter a aprendizagem facilitada por meio do curso misto.

Quando questionados sobre a adaptação do conteúdo ensinado na modalidade mista, $81,8 \%$ dos entrevistados responderam que se adaptaram com a metodologia blended learning, e os demais, representados por 18,2\%, mantiveram-se indiferentes, o que pode indicar a possibilidade de alguma dificuldade, mesmo não havendo declaração pontual a respeito da não adaptação. Isso se deve ao fato de haver uma necessidade de uma autoavaliação do estudante, visto que Valente (2014) já sinaliza para esse tipo de avaliação em cursos híbridos, em que se reconhece o nível de preparo do aluno e oportuniza o professor a trabalhar os conteúdos em que se apresentam maiores dificuldades na sala de aula.

Em outra questão, averiguou-se sobre a metodologia aplicada e os materiais pedagógicos disponibilizados, se os estudantes acreditavam serem coerentes com a proposta do curso ofertado, e a maioria das respostas $(90,9 \%)$ apontaram para a coerência de metodologia e materiais. Dessa forma, identificou-se a satisfação por parte dos entrevistados quanto a esse aspecto, tanto no ambiente online como nas aulas presenciais. O restante, representado por 9,1\% dos respondentes, demonstrou indiferença quanto essa questão.

Outro questionamento apontava a proposição de o curso misto possibilitar o aprendizado para o desenvolvimento de criações de moda, em que $72,7 \%$ respondeu que "sim", concordando com essa proposição, e os demais, $27,3 \%$ apresentaram-se indiferentes. Assim, nota-se um percentual positivo, no qual o curso misto é representativo para o aprendizado do aluno, o que possibilitaria sua aderência e aplicabilidade na área de moda, em conformidade com os objetivos do curso.

Uma das interrogações do questionário referia-se quanto à escolha de um novo possível curso, em que os respondentes optariam pela modalidade de sua preferência. Assim, 81,8\% optaram pela "modalidade mista", e os demais, representados por $18,2 \%$, escolheram a opção de novo curso "totalmente presen- 
cial". Mesmo assim percebe-se um grau de satisfação dos alunos quanto à modalidade híbrida, considerando que usualmente eles participam de cursos na forma tradicional de ensino, ou seja, modalidade presencial.

Do mesmo modo, os respondentes foram questionados sobre a indicação do curso na modalidade mista para outras pessoas, e $72,7 \%$ responderam que sim, indicariam, e os demais $27,3 \%$ optaram pela não indicação. Nesse caso, percebeu-se uma resistência, reconhecendo, mesmo que pequena, a preferência de alguns respondentes pelo sistema de ensino tradicional, modalidade presencial, em comparação à aceitação da modalidade de ensino mista.

As últimas questões estavam relacionadas diretamente com a satisfação quanto ao curso misto ofertado, considerando os aspectos discutidos nas etapas de sua construção. Os respondentes avaliaram satisfatoriamente o curso, não obtendo-se notas inferiores a cinco, em uma escala de 0 a 10 , na qual a nota zero representaria "muito insatisfeito", a nota cinco representaria "satisfeito" e a nota dez demonstraria a representação de " muito satisfeito".

Assim, a elaboração de um curso na modalidade mista, de acordo com essa investigação-ação, demonstrou em sua avaliação a satisfação dos respondentes em comparação ao mesmo curso na modalidade presencial. Cabe ressaltar que os discentes que avaliaram o curso já possuíam as competências do conteúdo proposto, visto que já cursaram este curso na modalidade presencial.

Nesse sentido, para as autoras da pesquisa, a aceitação dessa modalidade representa um resultado positivo em sua oferta. A modalidade de cursos mistos, blended learning, apesar de não ser recente, aponta oportunidades para maior interação, mais praticidade e oportuniza aos estudantes liberdade e autonomia para organizar seus estudos, facilitando a aprendizagem e respeitando as especificidades de cada um, em comparação ao estudo tradicional.

\section{CONSIDERAÇÕES FINAIS}

Com base no desafio proposto, a elaboração de um curso misto, e analisando a revisão bibliográfica apresentada, bem como a elaboração das etapas para a construção do curso, a aplicação e análise dos dados coletados a partir do questionário, percebe-se que o curso misto oferece aos alunos possibilidades de oportunidades de acesso ao ensino com qualidade, democratizando a aprendizagem, oportunizando a todos o acesso ao conhecimento.

Conforme observado nas respostas dos questionários, a essência da educação presencial ainda se mantém representativa, porém, a opção baseada na abordagem blended learning permite, ao mesmo tempo, as vantagens do contato face a face e a autonomia para que os alunos organizem seus estudos online, 
contribuindo para o seu bom andamento, em comparação à oferta na modalidade presencial. Através das respostas dos 11 estudantes egressos, conclui-se que o curso misto oferece uma satisfação maior que a modalidade presencial e ainda permite diferentes abordagens pedagógicas que podem ocorrer de forma assíncrona ou síncrona.

Esta investigação-ação apresenta limitações em função do tema e público participante escolhido, mas abre reflexões para que a modalidade de ensino misto possa ganhar espaço em diferentes cenários, ampliando horizontes para a aprendizagem e superando as modalidades de ensino tradicionais, que não comportam as exigências era digital. Um ensino inovador precisa estar comprometido com uma educação de qualidade e eficaz, inserida em um contexto educacional local e global, oferecendo aos aprendizes uma forma de ensino que responda às suas necessidades e as necessidades da sociedade atual.

\section{REFERÊNCIAS}

BARTOLOMÉ, A. Blended learning. Conceptos básicos. Píxel-Bit. Revista de Medios y Educación, Sevilla, v. 23, p. 7-20, 2004. Disponível em: <http://www.lmi.ub.es/personal/bartolome/articuloshtml/04_blended_learning/documentacion /1_bartolome. pdf>. Acesso em: 2 ago. 2016.

CASTRO, M. P. O Projeto Minerva e o desafio de ensinar matemática via rádio. 2007. Dissertação (Mestrado Profissional em Ensino de Matemática) - Pontifícia Universidade Católica de São Paulo, São Paulo, 2007.

CHAVES FILHO, H. et al. (Org.). Educação a distância em organizações públicas: mesaredonda de pesquisa-ação. 2006. Disponível em: <http://repositorio.enap.gov.br/handle/1/376>. Acesso em: 15 ago. 2016.

GIGLIO, K.; SOUZA, M. V. de. Mídias, redes sociais e ambientes virtuais: pensando a educação em rede. In: CONGRESSO BRASILEIRO DE ENSINO SUPERIOR A DISTÂNCIA (ESUD) - UNIREDE, 10., 2013, Belém. Anais... Belém: ESUD, 2013.

GONÇALVES, V. M. B. e-Learning: reflexões sobre cenários de aplicação. Biblioteca Digital IPB - Repositório Institucional do Instituto Politécnico de Bragança. 2007. Disponível em: <https://bibliotecadigital.ipb.pt/bitstream/10198/1383/1/artigo_vg. pdf $>$. Acesso em: 15 ago. 2016.

INSTITUTO NACIONAL DE ESTUDOS E PESQUISAS EDUCACIONAIS ANÍSIO TEIXEIRA (INEP). Censo Escolar, 2010. Brasília: MEC, 2011.

MACHADO, A. de B. et al. Orientação na educação a distância: uma análise da realidade brasileira, 2014. Revista da Universidade Vale do Rio Verde, Três Corações, v. 2, n. 12, p. 149-158, dez. 2014b. Disponível em: <http://revistas.unincor.br/index.php/ revistaunincor/article/view/1419/pdf_196>. Acesso em: 8 set. 2016.

MATEUS FILIPE, A. J.; ORVALHO. J. G. Blended-learning e aprendizagem colaborati- 
va no Ensino Superior. In: CONGRESSO IBEROAMERICANO DE INFORMÁTICA EDUCATIVA, 7., 2004, Monterrey. p. 216-225. Anais... Disponível em: <http:// www.ufrgs.br/niee/eventos/RIBIE/2004/comunicacao/com216-225.pdf>. Acesso em: 9 ago. 2016.

PADILHA, M. A. S. Os modelos de educação a distância no brasil: a Universidade Aberta do Brasil como um divisor de águas. Revista Reflexão e Ação, Santa Cruz do Sul, v. 21, n. esp., p. 82-103, jul./dez. 2013.

RABELLO, C. R. L.; HAGUENAUER, C. J. Sites de redes sociais e aprendizagem: possibilidades e limitações. Educaonline, Rio de Janeiro, v. 5, n. 3, p. 19-43, set./dez. 2011. Disponível em: <http://www.latec.ufrj.br/revistas/index.php?journal=educaonl ine\&page=article\&op=view\&path\%5B\%5D=189> Acesso em: 15 ago. 2016.

SALMON, G. E-moderating the key to teaching and learning online. 3. ed. New York: Routledge, 2011.

SANTOS, P. M.; BRAGA, M. M.; FERREIRA, M. V. A.; SPANHOL, F. J. An application model for digital television in e-learning. Journal of Communication and Computer, v. 8, p. 1079, 2011.

SPANHOL, G. K.; SPANHOL, F. J. Processos de produção de vídeo-aula. Renote. Revista Novas Tecnologias na Educação, v. 7, p. 1-9, 2009.

SUHR, I.; RIBEIRO, F. Reflexões e apontamentos sobre o papel da aula na Educação a Distância. Revista Intersaberes, Curitiba, v. 5, n. 9, p. 25-41, jan./jun. 2010. Disponível em: <http://www.uninter.com/intersaberes/index.php/revista/article/viewFile/ 160/127>. Acesso em: 9 ago. 2016.

TORI, R. Cursos híbridos ou blended learning. In: FORMIGA, M.; LITTO, F. Educação a distância: o estado da arte. São Paulo: Pearson Education, 2009.

TRIPP, D. Pesquisa-ação: uma introdução metodológica. Educação e Pesquisa, São Paulo, v. 31, n. 3, p. 443-466, dez. 2005. Disponível em: <http://www.scielo.br/scielo. php?script=sci_arttext $\&$ pid $=\$ 1517-97022005000300009 \& \operatorname{lng}=$ en $\&$ nrm $=$ iso $>$. Acesso em: 9 ago. 2016. DOI: <http://dx.doi.org/10.1590/S151797022005000300009>.

VALENTE, José Armando. Blended learning e as mudanças no Ensino Superior: a proposta da sala invertida. Educar em Revista, Curitiba, Edição Especial, n. 4/2014, Editora UFPR, p. 79-97, 2014. 


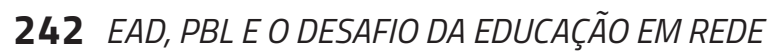

